\title{
Estudo e Análise da Fabricação de Concreto a Partir do Uso De Resíduos de Borracha de Pneus
}

\author{
Sâmia Rodor Marinho', Fernanda Lemes reis ${ }^{2}$; Lorena Resende Tomain ${ }^{3}$; Renata Franco de Medeiros ${ }^{4}$; \\ Carolina Oliveira Pinto ${ }^{5}$ \\ 1, 2, 3, 4, 5 Universidade de Uberaba \\ samiamarinhoo@hotmail.com; carolina.pinto@uniube
}

\section{1 - Introdução}

A reciclagem é, atualmente, uma das propostas mais utilizadas para que não haja acúmulo de resíduos de materiais inservíveis e a predação dos recursos naturais.

A indústria da construção civil, segundo estimativas, é responsável por 20 a $50 \%$ do consumo dos recursos naturais extraídos do planeta (JOHN, 2000).

A utilização de resíduos de pneus como material de construção é uma maneira de diversificar e aumentar a oferta de materiais de construção, viabilizando eventualmente reduções de preço que gera benefícios sociais adicionais através da política habitacional, uma vez que a grande parte dos componentes necessários para a construção de habitações podem ser produzidos com materiais sem grande sofisticação técnica.

A reutilização do pneu como agregado do concreto assume, então, um papel importante na preservação do meio ambiente, pois, além de diminuir a extração de recursos naturais, como a areia e a brita, também pode diminuir o acúmulo desses resíduos nas áreas urbanas. Esta situação pode ser favorecida pela adoção de medidas de incentivo específicas para a produção de habitações de baixa renda com o intuito de resolver o problema de déficit habitacional.

Assim, o uso de pneus triturados como agregado miúdo no concreto como substituto dos materiais de construção convencionais apresentam, além da alternativa à alocação de resíduos, é uma solução técnica com os seguintes benefícios para as edificações: densidade reduzida, melhor propriedade de drenagem e, melhor isolação térmica e acústica (DOS SANTOS, 2005).

O presente trabalho tem como objetivo mostrar a utilização da borracha do pneu como matériaprima na Construção Civil, primando a relação entre o termo sustentabilidade e o seu uso

\section{2 - Materiais e métodos}

O trabalho foi desenvolvido por meio de levantamentos na literatura acadêmica relacionados ao uso de pneus triturados como agregado miúdo no concreto substituindo da areia para a confecção de blocos para a construção de habitações populares publicados entre os anos de
1994 e 2011. Essas publicações foram buscadas em vários bancos de dados como scielo, periódicos capes, bibliotecas digitais da USP e UNICAMP, DNIT.

\section{3 - Resultados e discussão}

O uso do pó da borracha no concreto, obtido da moagem de pneus inservíveis, produz um material isolante, em função de sua baixa condutividade elétrica e sonora. O concreto com adição de borracha de pneu pode ser um material ideal quando submetido a efeitos de impacto e que não necessita de alta resistência mecânica.

Segre (2000 e 1999) realizou trabalhos com pó de borracha de pneus usados tratados superficialmente com hidróxido de sódio na pasta de cimento, obtendo vantagens quanto a absorção de água por capilaridade e resistência mecânica.

De uma maneira geral, observa-se que a introdução de borracha ao concreto provoca uma diminuição da resistência à compressão. Segundo Topçu (1994), a resistência à compressão diminui em torno de $50 \%$, se adicionada borrachas com granulometria fina e em torno de $60 \%$ se adicionado borrachas com granulometria grossa. Isto demonstra que a variação na resistência à compressão, também, depende da granulometria da borracha. Segundo Topçu \& Avcular (1997) a razão para a redução da resistência pode ser atribuída a ambos fatos: a redução da quantidade de material sólidos com capacidade de suportar carregamento e a concentração de tensões na pasta ao redor dos agregados de borracha.

Com os estudos realizados sobre 0 comportamento do concreto com borracha de pneus (DOS SANTOS, 2005), percebe-se que os primeiros trabalhos deram maior enfoque às propriedades mecânicas, dentre elas, a resistência mecânica à compressão. Assim, foi constatado em todos os trabalhos que, o concreto incorporado de borracha de pneus possui perda na resistência à compressão e que esta perda aumenta de acordo com uma maior substituição dos agregados pela borracha, porém, com cerca de 10 a $15 \%$ de adição de borracha de pneu em agregado miúdo se observou resultados bastante satisfatórios.

Outros estudos descrevem desempenho da borracha de pneus em relação ao fogo. Concluíram que a adição da borracha diminui a

www.uniube.br/entec - UNIUBE Campus Aeroporto - Uberaba/MG 
forma frágil de ruptura do concreto de alta resistência, assim como a ocorrência do spalling. Ensaios termogravimétricos também indicaram que o aumento da quantidade de borracha, diminui a temperatura alcançada entre a parte exposta ao aquecimento e a parte exposta à temperatura ambiente. Dessa forma, pode-se obter maior segurança em elementos estruturais contra o fogo. (HERNÁNDEZ-OLIVARES; BARLUENGA ,2003).

O pó da borracha pode ser empregado na construção civil como isolante estrutural, pois veda a propagação de tensões, devido a sua capacidade de absorver energia 8.000 vezes maior que os metais (SEGRE, 1999).

\section{4 - Considerações finais}

A utilização de agregados reciclados na produção de concreto é satisfatória para redução de poluentes no meio ambiente.

A análise da temperatura de fulgor revelou que as temperaturas de amolecimento e de combustão ocorrem em uma faixa em que o concreto já tem suas propriedades deficientes.

As perdas percentuais nas propriedades mecânicas de resistência a compressão, resistência tração e módulo de elasticidade eram esperados. Porém, pode-se observar que a borracha atribuiu ao concreto a capacidade de romper sem que houvesse movimentos bruscos no pistão de carregamento, pois o concreto ficou com mais ductilidade.

A produção de agregados que se destaca, foi a de teores de 10 a $15 \%$ de adição de resíduos da borracha de pneu em substituição a areia. Apenas cuidados com a trabalhabilidade devem ser observados.

Verificou-se que em termos de tenacidade o aumento não foi significativo. Porém observou-se um aumento na deformação de ruptura de flexão do concreto e uma tendência de estabilização nos danos causados pelo impacto. Isto leva a crer que aumentando o tamanho das fibras os resultados que dependem da tenacidade podem ser melhorados.

Com os resultados obtidos pode-se considerar que os testes apresentam qualidades para sua utilização como material para a fabricação de calçadas, piso de ciclovias, meio-fio, até em muros e peças pré-fabricadas. No entanto, não foi realizado avaliações do comportamento deste concreto em relação ao intemperismo, recomendando estudos.

\section{5 - Referências.}

DOS SANTOS, A. C. (2005); Avaliação do Comportamento do Concreto com Adição de Borracha Obtida a Partir da Reciclagem de Pneus com Aplicação em Placas Pré-moldadas. Tese (Mestrado em Engenharia Civil) - Universidade Ferderal do Alagoas, Maceió/AL.

GRANZOTTO, L. (2010); Concreto com adições de borracha: uma alternativa ecologicamente viável. Dissertação apresentada ao Programa de Pós-Graduação em Engenharia Urbana como requisito parcial para obtenção do título de Mestre em Engenharia Urbana - Universidade Estadual de Maringá, Maringá/PR.

HERNÁNDEZ-OLIVARES, F.; BARLUENGA, G. (2003); Fire Performance of Recycled RubberFilled High-Strength Concrete; http://www.periodicos. capes.gov.br/, acesso em: 10 de setembro 2014.

JOHN, V. M. Reciclagem de resíduos na construção civil: Contribuição para metodologia de pesquisa e desenvolvimento. São Paulo, 2000. 113p. Tese (Livre Docência) - Escola Politécnica da Universidade de São Paulo. Departamento de Engenharia de Construção Civil.

SEGRE, N. C. (1999); Reutilização de Borracha de Pneus Usados como Adição em Pasta de Cimento. Tese (Doutorado em Química) Universidade Estadual de Campinas, São Paulo/SP.

TOPÇU, I. B. (1994); The Properties of Rubberized Concrete; http://www.periodicos. capes.gov.br, acesso em: 10 de setembro 2014.

TOPÇU, I. B. \& AVCULAR, N. (1997); Collision Behaviours of Rubberized Concrete; http://www.periodicos.capes.gov.br/, acesso em: 10 de setembro 2014.

TOPÇU, I. B. \& AVCULAR, N. (1997); Analysis of Rubberized Concrete as a Compo- site Material; http://www.periodicos.capes.gov.br/ , acesso em: 10 de setembro 2014.

\section{Agradecimentos}

À instituição UNIUBE pela realização das medidas e empréstimo de equipamentos. 